\title{
Teaching conceptions on the use of digital technologies as a teaching resource in physical education in public schools of Minas Gerais, Brazil
}

\author{
Marcos Rincon Voelzke ${ }^{1,2}$, Arilson Paganotti ${ }^{1,3}$, and Adriana Maia Marcossi Assis ${ }^{3}$ \\ ${ }^{1}$ Universidade Cruzeiro do Sul, São Paulo, Brazil \\ ${ }^{2}$ Institut für Geophysik und extraterrestrische Physik, Technische Universität Braunschweig, \\ Germany \\ ${ }^{3}$ Instituto Federal de Minas Gerais, Congonhas, Brazil
}

\begin{abstract}
It is observed that the technologies have invaded the classrooms, providing increasingly attractive teaching methods. Technologies have challenged school institutions to keep up with this new reality. In some cases, the technologies offered aim, to a certain extent, to meet some educational needs of students and soften deficiencies in classroom teaching. The arrival of digital technologies in classrooms brings great advances, but also brings many uncertainties and insecurities, giving rise to new tensions, new possibilities and new challenges. With today's technologies, the school environment can transform into a meaningful, face-to-face and digital learning environment, making students more active, motivating them to learn and search all the time. The present work aims to present the advantages and disadvantages of these digital methods, as well as to demonstrate the applicability of these technologies in the current daily life of school institutions. It also presents some important aspects about the use of technologies in the learning process, discussing how the use of virtual simulations software can contribute to the teaching of Physics. To obtain data from the students, a questionnaire with seven questions was used.
\end{abstract}

\section{Introduction}

Every day more information and communication technologies invade people's daily lives. These new technologies can provide new perspectives, broadening the view of some people on certain subjects, and here, the objective of the present work, is precisely to demonstrate how these technologies can influence teaching, contributing to learning.

It is important to highlight the role of technologies in the school environment, as it aims to support the new teaching pattern, ie, technology must support students in their learning, constituting another educational resource. 
According to [1] education and the education system have undergone many changes. The advancement of technology has popularized access to information by changing our way of living and consequently our way of learning.

According to [2]: In the current stage of technological and economical development, new educational paradigms that include the insertion of information and communication technologies in educational environments emerge. Informatics in education is a controversial subject and marked by contradictions among educators, but it must be incorporated into the teaching and learning process.

Technology is widely used in today's society as a facilitator of everyday tasks, being increasingly inserted in work, leisure, politics and also education, being the focus of this research.

The purpose of this study was to verify the use of digital technologies in the teaching of physics in state public schools in Minas Gerais, and to identify the challenges and facilities provided by this insertion.

Additionally, we aimed to verify the relation of the students with the technological resources offered to them and if these resources favor a meaningful learning. [3].

Students usually have difficulties in understanding and interpreting the physical concepts studied in science, with this it is considered the use of educational technological resources as a medium that can facilitate the understanding of these concepts and soften the difficulties of teaching and learning of the students.

On the subject, [4] mentions: Educational technology is understood as the set of techniques, processes and methods that use digital means and other resources as tools of support applied to teaching, with the possibility of acting methodically between who teaches and who learns.

The use of technologies can arouse students' interest not only within the classroom, but also arouse ongoing interest in learning. According to [1]: "The student developing the habit of research and interest in information will naturally develop the need for learning, becoming a questioning and critical being of the reality that surrounds him."

\section{Methods}

In order to investigate how the use of digital technologies can influence the significant learning of physics contents, a questionnaire with seven questions was applied to students of the state network in the cities of Congonhas and São Brás do Suaçuí, located inside of Minas Gerais, Brazil. In total, four schools participated in the research, with three schools located in the city of Congonhas and one school located in the city of São Brás do Suaçuí. A total of 159 students from a first, second and third year high school classes were surveyed.

The applied questionnaire had objective and discursive questions, among which were verified the positions of the students in relation to the use of the digital technologies in the teaching of Physics.

In some questions the students were questioned about the use of technologies in everyday school and outside, what technological devices were used and whether teachers used digital technologies in their classes. Another research question was to verify if the school offered a laboratory of computer science for the frequent use of the students.

The analysis of the data obtained by the questionnaire applied to the students was carried out based on the Bardin content analysis techniques [5], being made a grouping and classification of the similar answers, these being represented in graphs and tables. 


\section{Results and Discussions}

For the analysis of the answers, the schools participating in the research were: School A (32 students), School B (39 students), School C (18 students) and School D (70 students). In this denomination we indicate the number of students participating in the research per school. The first question asked if students were using any computer equipment, "Which computer equipment do you most use?" The results are shown in Figure 1.

Figure 1: Computer equipment in the schools surveyed

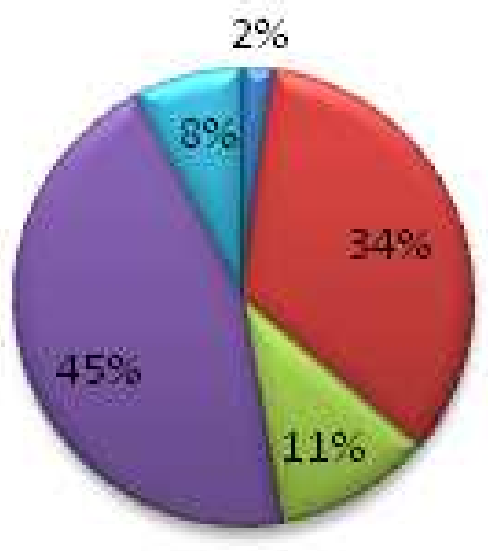

Dido not have

Desktop computer

Tablet

Smatrphone

Others

It was verified in the graph of Figure 1 that the smartphone (45\%), the desktop computer $(34 \%)$ and the tablet (11\%) were the resources most used by the students.

The third question asked the students if they had access to the school's computer lab to carry out school activities. The results are shown in Figure 2.

Figure 2: Students' access to computer laboratories in schools

\begin{tabular}{|c|c|c|c|c|}
\hline \multicolumn{5}{|l|}{70} \\
\hline \multirow{2}{*}{\multicolumn{5}{|c|}{$\begin{array}{l}60 \\
50\end{array}$}} \\
\hline \multirow{2}{*}{\multicolumn{4}{|c|}{40}} & \\
\hline \multirow{2}{*}{\multicolumn{4}{|c|}{30}} & \\
\hline & $\nabla$ & & & \\
\hline \multicolumn{5}{|l|}{$\begin{array}{l}20 \\
10\end{array}$} \\
\hline & & $\Gamma$ & & $\nabla$ \\
\hline & School A & School B & School C & School D \\
\hline$\square$ No & 29 & 31 & 18 & 7 \\
\hline$\nabla$ I could not answer & 0 & 1 & 0 & 0 \\
\hline$\nabla$ Yes & 3 & 7 & 0 & 63 \\
\hline
\end{tabular}


From the results obtained, it is verified that the students of school D have greater access to the information technology laboratories, whereas the students of schools A, B and C in the majority do not have. It is noticed that the lack of structure of the schools can contribute to the learning difficulties of the students.

Question number 4 had as objective to verify which items that the students consider more interesting for the learning of Physics. They could choose from a list of terms provided. "Among the items below, what do you think would be interesting to learn physics more easily?" Figure 3 represents the variability of responses given by students. A greater choice was observed for the item dealing with experiments that illustrate everyday physics. This option appears with relevance in the charts of the four surveyed schools, with emphasis on school D. It is observed that the sum of the values expressed in Figure 3, extrapolated the 100 percent. This is because students could choose more than one answer option from the offered ones.

Figure 3: List of the most interesting means, considered by the students, to learn Physics.

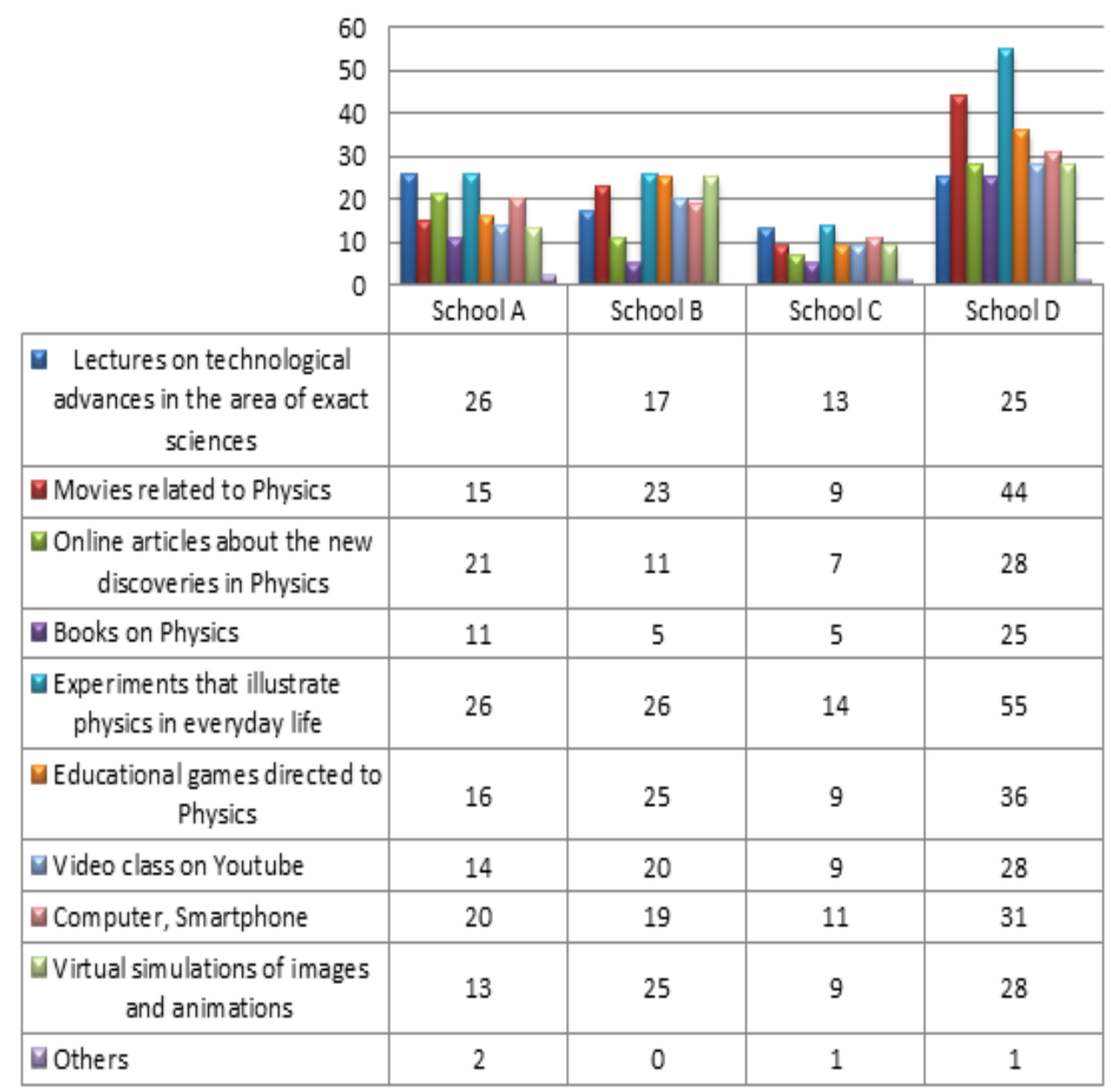


Question number 5 had as objective to verify, in the opinion of the students, if the teachers use some technological resource next to the teaching of Physics during the classes in the school routine.

According to the data obtained and shown in Table 1, most of the students stated that the teachers of these surveyed schools, in general, do not use technological resources to aid teaching, that is, most of the classes are given in an expositive way using the blackboard .

Table 1: Use of technological resources to aid the teaching of Physics in schools.

\begin{tabular}{|c|c|c|c|}
\hline School & $\begin{array}{c}\text { Yes. It used a multimedia projector, } \\
\text { computer, experiments, lectures, } \\
\text { simulators. }\end{array}$ & No & Did not know \\
\hline A & 1 & 31 & 0 \\
\hline B & 10 & 29 & 0 \\
\hline C & 4 & 13 & 1 \\
\hline D & 26 & 42 & 2 \\
\hline
\end{tabular}

Questions 6 and 7 of the applied questionnaire aimed to analyse how many students have participated during their student life in interactive physics classes using digital technologies, and if this facilitated their learning. (Figure 4)

Figure 4: Example of a response given by a student at school C

06. Se você já participou de aulas com simulações virtuais interativas de Física, responda. 0 uso de Simulações de Imagens durante o ensino facilitou o seu aprendizado? Justifique.

Sim. Calemunaus fáeil de apunder

07. Você considera que o uso de tecnologias digitais no ensino pode favorecer o aprendizado dos conteúdos de física, junto aos alunos? Justifique.

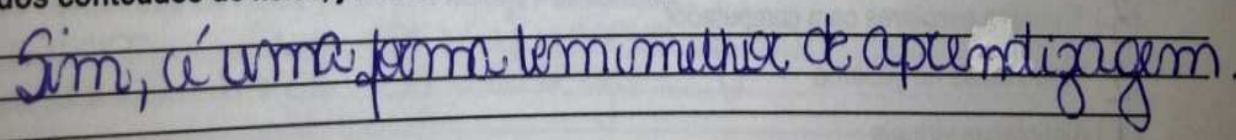




\section{Conclusion}

We carried out a survey under high school students of four different schools on the use of digital technologies in the study physics. In total 159 students filled out a questionnaire. The results indicate that the students are interested in the possibility of using digital technological resources that can contribute to the learning of the concepts of Physics. This is justified by the everyday use of digital technologies such as smarphones, tablets and computers.

The results obtained with the application of the questionnaires showed that the digital technologies can contribute to the teaching of Physics, since these teaching methods are well received by the students, who find in these new ways to learn an opportunity to study with pleasure, characterizing the basic concepts of meaningful learning theory.

\section{Bibliographic References}

1. A. Lúcia Silveira. New Technologies, New Students, New Teachers? Reflecting on the Teacher's Role in Contemporaneity. Sao Paulo. 2012. Available at: <http: // C: /Users/Marianna/Downloads/4668.pdf>. Accessed on 17 Dec 2015.

2. S. Marco Aurélio; K. Aristeia Mariane. Potentials and Challenges of Networks Supporting the Implantation of ICT Culture in Teacher Training. Available at:http://www.unicruz.edu.br/seminario/anais/2013/MULTIDISCIPLINAR/Poster/POT ENCIALIDADES\%20E\%20DESAFIOS\%20DAS\%20REDES\%20DE\%20APOIO\%20 A. Accessed on Dec 17, 2015.

3. M. Marco Antônio. Critical Significant Learning. Porto Alegre: Institute of Physics of UFRGS. 2005. Available at: <http://www.if.ufrgs.br/ moreira/apsigcritport.pdf $>$. Accessed on 17 Dec 2015.

4. P. Vera Lúcia L. De Oliveira. Teaching with the Use of Technology. Rio de Janeiro 2008. Available at: http://www.apev.com.br/ensinar-com-o-uso-da-tecnologia/. Accessed on 03 Feb 2016.

5. B. Laurence. Content Analysis. Lisbon: Issues Seventy, 1994. 